\title{
Prevalence of smoking among universities students of Shahroud in 2010
}

\author{
Saeid Nazemi ${ }^{1^{*}}$, Reza Chaman ${ }^{2}$ \\ ${ }^{1}$ Department of Environmental Health, Faculty of Health, Shahroud University of Medical Science, Shahroud, Iran; \\ *Corresponding Author: Saied_Nazemi@yahoo.com \\ ${ }^{2}$ Department of Basic Sciences, School of Medicine, Shahroud University of Medical Science, Shahroud, Ian
}

Received 18 January 2012; revised 28 February 2012; accepted 16 March 2012

\begin{abstract}
This study in $\mathbf{2 0 1 0}$ determined the prevalence of smoking and its associated factors among universities students in Shahroud located in the North Eastern of Iran. 1800 students were selected randomly among 20000 students of Shahroud universities, to complete a questionnaire Which was prepared based on the Global Youth Tobacco Survey. The prevalence of current smoking was $20 \%$ ( $80 \%$ male and $20 \%$ female). The most important factors in the tendency to smoking were: friends smoking, stress, separation from family and fun.
\end{abstract}

Keywords: Prevalence; Smoking; Students; Shahroud Insert

\section{INTRODUCTION}

Cigarette smoking is considered a major public health hazard in the world. It is among the main preventable causes of untimely death, morbidity and mortality worldwide. About 5 million deaths occur annually due to cigarette smoking. If the pattern of tobacco consumption continues at the same pace as today, the morbidity and mortality rates will be doubled (10 million people per year) by the year $2020[1,2]$ and 7 million of which will occur in developing countries [3]. Due to high proportion of young In the Islamic Republic of Iran, tobacco control and prevention programmes are very important [4].

Several studies showed increasing trend in smoking among Iranian youth [5-7].

There has been a dramatic increase over the past decade in the numbers of college-age smokers [8]. Based on recent studies the prevalence of smoking increases from the first year to the final year among university students, which underlines the fact that the early years at university are important for targeting anti-smoking activities $[9,10]$. Students who enter college as non-smokers are
$40 \%$ less likely to begin smoking if they live in a smokefree campus [11].

Cigarette consumption shows an increasing trend in many Middle East and North Africa countries [12].

The World Health Organization has reported prevalence of smoking among young people in the Eastern Mediterranean as following: $26.6 \%$ in Iran, $20.9 \%$ in Kuwait, $17.2 \%$ in Iraq, $10.1 \%$ in Pakistan and $15.9 \%$ in Saudi Arabia [13]. However, the trend and pattern of smoking as well as the quitting rate especially among college students are largely unknown in many of these countries.

This study was carried out to determine the prevalence and it's related factors among University students of Shahroud city.

Text styles are provided. The formatter will need to create these components, incorporating the applicable criteria that follow.

\section{METHODS}

This study was coducted as a cross-sectional descriptive study during a 16-week period (from mid-March 2010 to mid-June 2010). The total number of university students in Shahroud are about 20000.The sample size was estimated as 1800 subjects based on: prevalence $=$ $20 \%, \alpha=0.05$ and precision ( $d=0.15)$. The subjects were selected randomly and proportional to size of cash University students. They have to complete the questionnaire which was an Iranian Global Youth Tobacco Survey (GYTS) questionnaire [4]. The data analysis was performed using SPSS, version 11.5 software.

\section{RESULTS}

There were 1800 university students, including 1076 boys (60\%) and 724 girls (40\%). The age range was 18 35 years and the mean age was $28.5 \pm 3.6$ years.

The prevalence of smoking among the students was $20 \%$. For any type of tobacco $20 \%$ of respondents were current smokers, $80 \%$ non smokers. For cigarettes, 39\% 
were current smokers, while for Hookah (water pipe) the corresponding prevalences were $31 \%$ and 5\% for Pipe.

Table 1 shows the Distribution of the characteristics of the smoker and nonsmoker groups. Significantly more current smokers were in older age groups 20 - 25 years (72\%) and 25+ years (9\%) compared with the total sample $(\mathrm{P}<0.001)$. Students at the university of Azad and Industrial had the highest prevalence of smoking compared with those at other university; the lowest prevalences were at the university of medical sciences and quranic sciences $(\mathrm{P}<0.001)$.

For cigarette smokers the mean daily cost was 10000 (1\$) Iranian riyals (61\%).

There were significant differences between smoking and their Degree $(\mathrm{P}<0.001)$ there was a significant difference between smoking and Status married $(\mathrm{P}<0.001)$. There were significant differences between smoking and their family residence and students residence $(\mathrm{P}<0.001)$. A total of 390 (20\%) students were smokers; 310 boys (29\%) and 80 girls (11\%) $(\mathrm{P}<0.001)$.

Among the 390 smokers, 96\% had more than 1 other family members who also smoked $(\mathrm{P}<0.001)$.

Of the smokers, 122 (31\%) lived with both their parents $(\mathrm{P}<0.0001)$. Thus, significantly more smokers lived with a single parent (due to the death of a parent or se- paration) ( $\mathrm{P}<0.001)$. Table 2 shows the Distribution of the reasons for smoking.

The most important predictive factors for smoking were: having a family member who smokes, highest family income, occupation, level education of father and mother, education degree and status married.

\section{DISCUSSION}

In this research, the prevalence of tobacco smoking in our students (20\%) was lower than rates reported in a previous study of students in Iran. Another study of university students of Kerman and Tehran during 2001-2005 showed that $22.7 \%$ and $22.1 \%$ were smokers. In the GYTS study conducted in 1999 among the youth of 13 countries, occasional smoking was reported by between $10 \%-33 \%$ of young people.

However, in the Iranian national health survey performed from 1991-99, the prevalence of cigarette smoking had declined from $12.5 \%$ to $14.3 \%$ [10].

In our research the prevalence of daily cigarette smoking among this group of 20 - 25 year-olds was greater in boys than girls (29\% versus $80 \%$ ). This finding shows that the risk of trying cigarette smoking is similar in boys and girls, but boys in this age group are more likely to

Table 1. Distribution of the characteristics of the smoker and non smoker groups.

\begin{tabular}{|c|c|c|c|c|c|}
\hline \multirow{2}{*}{ Variable } & \multicolumn{2}{|c|}{ Smoker $(n=390)$} & \multicolumn{2}{|c|}{ Nonsmoker $(\mathrm{n}=1410)$} & \multirow{2}{*}{ Statistics } \\
\hline & No. & $\%$ & No. & $\%$ & \\
\hline \multicolumn{6}{|l|}{ Age group } \\
\hline$<20$ & 60 & 16 & 157 & 11 & \multirow{4}{*}{$\mathrm{X}^{2}=28.2 ; \mathrm{df}=4 ; \mathrm{P}<0.001$} \\
\hline $20-25$ & 280 & 72 & 983 & 70 & \\
\hline $25-30$ & 38 & 9 & 223 & 16 & \\
\hline $30+$ & 12 & 3 & 46 & 3 & \\
\hline \multicolumn{6}{|l|}{ Degree } \\
\hline Associate & 49 & 12.6 & 208 & 15 & \multirow{4}{*}{$X^{2}=13.1 ; d f=3 ; P<0.001$} \\
\hline $\mathrm{BA}$ & 310 & 79.7 & 1110 & 79 & \\
\hline MA & 16 & 4.1 & 76 & 5.5 & \\
\hline $\mathrm{PhD}$ & 14 & 3.6 & 16 & 1 & \\
\hline \multicolumn{6}{|l|}{ Family residence } \\
\hline Urban & 354 & 91 & 1324 & 94 & \multirow[t]{2}{*}{$\mathrm{X}^{2}=4.1 ; \mathrm{df}=1 ; \mathrm{P}<0.001$} \\
\hline Rural & 35 & 9 & 86 & 6 & \\
\hline \multicolumn{6}{|l|}{ Students residence } \\
\hline For famill & 122 & 31 & 523 & 37 & \multirow{3}{*}{$X^{2}=88.01 ; d f=3 ; P<0.001$} \\
\hline Renting a home-alone & 194 & 50 & 381 & 27 & \\
\hline Hostel & 74 & 19 & 506 & 36 & \\
\hline
\end{tabular}




\section{Continued}

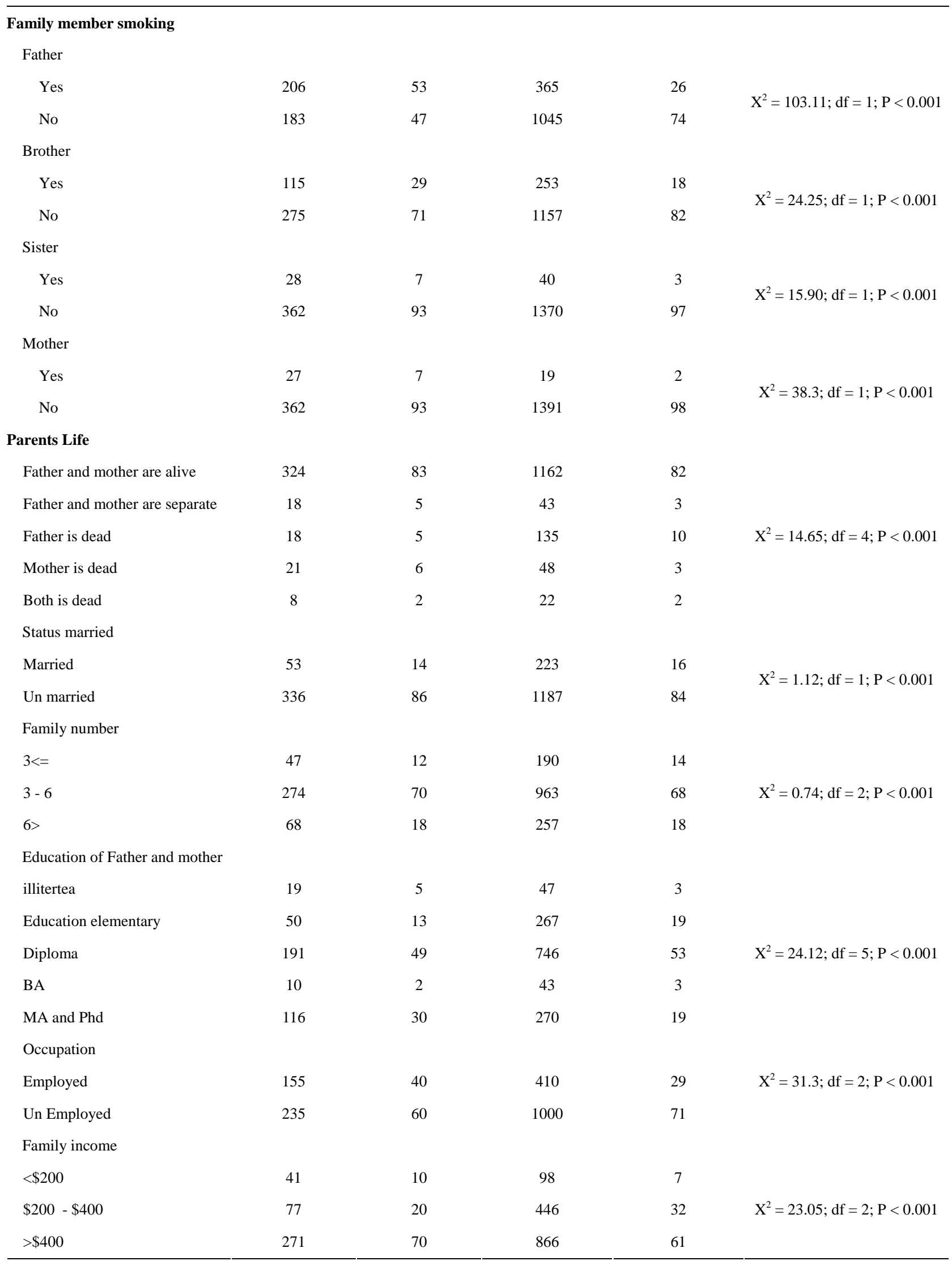


Table 2. Distribution of the reasons for smoking.

\begin{tabular}{cccc}
\hline $\begin{array}{c}\text { Reasons for } \\
\text { smoking }\end{array}$ & $\mathrm{N}$ & $\%$ & Statistics \\
\hline Entertainment & 174 & 44 & \\
Friend & 95 & 24 & $\mathrm{X}^{2}=75.82 ; \mathrm{df}=5 ;$ \\
Stress & 68 & 17 & $\mathrm{P}<0.001$ \\
All & 53 & 15 & \\
\hline
\end{tabular}

become dependent on smoking. Higher rates of smoking among adult males compared with females has been seen in studies in Poland (26.4\% versus $41.2 \%$ ) [11] and in other Mediterranean countries, North Africa and the Middle East (60\% versus 20\%) [14]. In another study of the university students in Turkey, the prevalence of occasional smoking in boys and girls were $46 \%$ and $24 \%$ respectively $[15,16]$. Friends' behaviour and attitudes have also been shown in a large number of studies to be a particularly powerful force in shaping behaviour [17-19].

There was a significant statistical relationship between cigarette smoking and the lifestyle of the students. living with both parents or a single parent. We can hypothesize that living in a supportive and friendly family environment is a significant factor in preventing smoking in youth. Smoking by parents and brother and sister seems to be important in the initiation as well as the continuation of smoking. Bauman et al. found that student whose parents smoked were almost twice as likely to smoke as those whose parents had never smoked [20]. Kandel et al. found that both maternal smoking and the quality of parent-child interaction influenced the current smoking status among adolescents [21]. These finding are consistent with this study as current smokers had twice the risk when relatives, especially family, were smokers. We also observed that more students who had tried smoking had family members who also smoked compared with those that never smoked. This suggests that imitation plays an important role in the initiation of smoking in youth [16].

Our results show that the prevalence of smoking varied across students at different university, which is consistent with other studies in Iran [5].

These findings were confirmed in the regression analysis, as the significant predictive factors for smoking were presence of more than 1 smoker among the family members, having a brother or sister that smokes and living with a single parent. Therefore, it can be concluded that family environment is an important factor influenceing the smoking behaviour of youth.

\section{CONCLUSION}

In summary, the overall reported prevalence of daily cigarette smoking university students in Shahroud (20\%) is not especially high compared with figures reported from other countries. However, due to the large number of daily smokers who will become addicted to cigarettes in the future and because of the limited health education and prevention programmes addressing smoking in the Islamic Republic of Iran, this figure is concerning. Targeted preventive and educational interventions, for example through the mass media, are needed.

\section{ACKNOWLEDGEMENTS}

This research was supported by Shahroud university of medical sciences. We would appreciate all the partners of health center who sympathetically helped us in all the processes of this research. We also appreciate the students who took part in this study.

\section{REFERENCES}

[1] Christophi, C.A., Kolokotroni, O., Alpert, H.R., Warren, C.W., Jones, N.R., Demokritou, P., et al. (2008) Prevalence and social environment of cigarette smoking in $\mathrm{Cy}$ prus youth. BMC Public Health, 8, 190. doi:10.1186/1471-2458-8-190

[2] Pampel, FC. (2002) Patterns of tobacco use in the early epidemic stages: Malawi and Zambia, 2000-2002. American Journal of Public Health, 95, 1009-1015. doi:10.2105/AJPH.2004.056895

[3] Rozi, S., Butt, Z.A. and Akhtar, S. (2007) Correlates of cigarette smoking among male college students in Karachi, Pakistan. BMC Public Health, 7, 312. doi:10.1186/1471-2458-7-312

[4] Global Youth Tabacco Survey Collaborative Group (2002) Tobacco use among youth: A cross country comparison. Tobacco Control, 11, 252-270. doi:10.1136/tc.11.3.252

[5] Masjedi, M.R., Azaripoor, H., Heydari, G.H., Alinejad, S. and Velayati, A.A. (2002) Evaluation of smoking prevalence among the students of Tehran Universities. Journal of Medical Council, 20, 283-87.

[6] Heydari, Gh., Sharifi, H., Hosseini, M., Masjedi and M.R. (2004) The attitude of Tehran's high school students about smoking. Respiratory Journal, 11, 29-36.

[7] Ramezankhani, A., Zaboli, F., Zarghi, A., Masjedi, M. and Heydari, R. (2010) Smoking habits of adolescent students in Tehran. Tanaffos, 9, 33-42

[8] Houston, T.P., Kolbe, L.J. and Eriksen, M.P. (1998) Tobacco-use cessation in the 90s-not "adults only" anymore. Preventive Medicine, 27, Al-A2.

[9] Asian, D., et al. (2006) Prevalence and determinant of adolescent smoking in Ankara, Turkey. Turkish Journal of Cancer, 36, 49-56.

[10] Yegenoglu, S., et al. (2006) What is behind smoking among pharmacy students: A quantitative and qualitative study from Turkey? Substance Use and Misuse, 41, 405414. doi:10.1080/10826080500409142

[11] The Health Council (2003) Special report of the Health Council concerning a tobacco free campus. The 614th Regular Meeting of the Faculty Senate, 13 February 2003, 
Accessed 10 November 2009.

http://www.umass.edu/senate/fs docs/SEN DOC N0 03 -014TOBACCO_FRELpdf

[12] Economics of Tobacco for the Middle East and North Africa (MNA) Region (2001) Regional report: Middle East and North Africa (MNA), 18 May 2001.

http://siteresources.worldbank.org/

[13] WHO. (2009) WHO report: Tobacco epidemic health dimensions, tobaccois a greater cause of death and disability than any single disease. WHO, Geneva, 203-220.

[14] Charles, W.W., et al. (2000) Tobacco use by youth: A surveillance report from the GlobalYouth Tobacco Survey project. Bulletin of the World Health Organization, 78, 867-880.

[15] Mohammad, K., et al. (2000) Changes observed in the pattern of smoking in Iran during 1991-1999, based on National Health and Disease Surveys. Hakim Journal, 197, 290-294.

[16] WHO (1999) World Health Organization International Consultation on Environmental Tobacco Smoke (ETS) and Child Health, World Health Organization, Geneva, 11-14 January 1999, 6-11.
[17] Tessier, J.F., Nejjari, C. and Bennani-Othman, M. (1999) Smoking in Mediterranean countries: Europe, North Africa and the Middle East. Results from a co-operative study. International Journal of Tuberculosis and Lung Disease, 3, 927-937.

[18] Ziaee, P., Hatamizadeh, N. and Dolatabadi, Sh. (2001) Rate of cigarette smoking and the age of first smoking experience among the high school students of Tehran during 1998-1999. Hakim Journal, 2, 78-84.

[19] Urberg, K.A., et al. (2003) A two stage model of peer influence in adolescent substance use. Individual and relationship-specific differences in susceptibility to influence. Addictive Behaviours, 28, 1243-1256. doi:10.1016/S0306-4603(02)00256-3

[20] Bauman, K.E., et al. (1990) Effect of parental smoking classification on the association between parental and adolescent smoking. Addictive Behaviours, 15, 413-422. doi:10.1016/0306-4603(90)90027-U

[21] Kandel, D. and Wu, P. (1995) The contributions of mothers and fathers to the intergenerational transmission of cigarette smoking in adolescence. Journal of Research on Adolescence, 52, 225-252. 